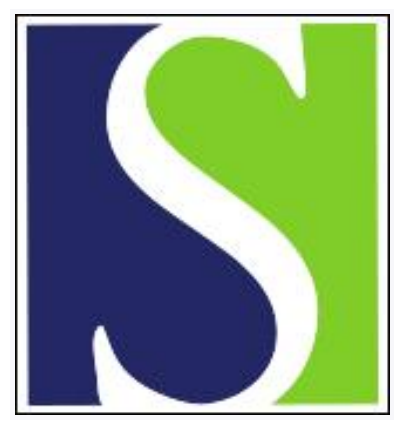

Scand J Work Environ Health 2009;35(4):284-293

https://doi.org/10.5271/sjweh.1334

Published online: 29 May 2009, Issue date: 31 Jul 2009

The development of the psychosocial work environment in Denmark from 1997 to 2005

by Pejtersen JH, Kristensen TS

Affiliation: National Research Centre for the Working Environment, Lerso Parkalle 105, DK-2100 Copenhagen, Denmark

Refers to the following texts of the Journal: 2006;32(6):421-430

2005;31(6):438-449 2004;30(2):85-128 2003;29(4):270-279

2001;27(3):161-213

The following articles refer to this text: 2009;35(4):241-243;

2010;36(6):433-434; 2021;47(5):335-348; 2021;47(5):329-333

Key terms: Denmark; psychosocial dimension; psychosocial work environment; questionnaire survey; review; secular trend; stress; systematic review; time trend; work environment

This article in PubMed: www.ncbi.nlm.nih.gov/pubmed/19479116

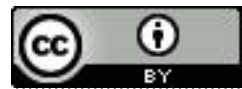




\title{
The development of the psychosocial work environment in Denmark from 1997 to 2005
}

\author{
by Jan H Pejtersen, PhD, ${ }^{1}$ Tage S Kristensen, DrMed ${ }^{1}$
}

Pejtersen JH, Kristensen TS. The development of the psychosocial work environment in Denmark from 1997 to 2005. Scand J Work Environ Health 2009;35(4):284-293.

\begin{abstract}
Objective The aim of the study was to elucidate the development of the psychosocial work environment in Denmark from 1997 to 2005.

Methods The analyses were based on two national questionnaire surveys $\left(\mathrm{N}_{1}=1062 ; \mathrm{N}_{2}=3517\right)$ of randomly selected employees who completed the Copenhagen Psychosocial Questionnaire. The psychosocial work environment was described by 19 scales and 6 single items.

Results Quality of leadership and social support from supervisors were the only dimensions that saw improvements. The negative developments were: higher work pace, less influence (job control), less possibilities for development (skill discretion), lower level of meaning of work, more role conflicts, decreased role clarity, reduced sense of community, less social support from colleagues, increased conflicts at work, more threats of violence, and more slander and gossip.

Conclusions The psychosocial work environment in Denmark deteriorated during the period 1997-2005. This deterioration was seen not just among certain groups of employees but in all subgroups, incorporating gender, age, and socioeconomic status. The negative development of a country's psychosocial work environment is worrying; as such, there is a strong need to change this negative trend.
\end{abstract}

Key terms psychosocial dimension; psychosocial work environment; questionnaire survey; secular trend; stress; systematic review; time trend.

According to a recent report from the National Institute for Occupational Safety and Health in the United States, the organization of work has undergone "revolutionary changes" during the last two decades (1). Significant developments include: the increased use of downsizing and outsourcing; the introduction of strategic technologies such as lean production, total quality management, and just-in-time inventory management; the use of temporary job contracts; and (in the US) longer working hours $(2,3)$. These developments are believed to have impacted negatively the quality of the psychosocial work environment by resulting in a higher workload and greater time pressure, increased speed of change, less predictability, and decreased job security. On the other hand, modern workplaces may also offer increased flexibility, more responsible work, greater learning opportunities and more control due to flatter organizational hierarchies and the use of more participative management practices $(1,4)$. However, these developments may take place simultaneously and/or affect different segments of the labor force.

A number of empirical studies have shed light on the development of the psychosocial work environment since 1970. This is complicated because there are many psychosocial factors at work and the development may differ so that some factors show positive changes and others negative. The development may also differ from one country to the next; it may even differ between sectors in the same country, and the development may be positive during one period but negative during another. Keeping these reservations in mind, the literature does seem to paint a rather clear picture of the most important developments.

In the US, the General Social Survey (1989 and 1998) showed a decrease in job security and an increase in exhaustion after work (4), although the respondents

1 National Research Centre for the Working Environment, Lerso Parkalle 105, DK-2100 Copenhagen Ø, Denmark.

Correspondence and reprint orders to: Dr JH Pejtersen, National Research Centre for the Working Environment, Lerso Parkalle 105, DK-2100 Copenhagen Ø, Denmark. [E-mail: jhp@nrcwe.dk] 
reported better relations with management as well as co-workers. The 1997 National Study of the Changing Workforce demonstrated an increase in job demands, decision authority, and skill discretion between 1977 and 1997 (5).

With regard to Europe, surveys carried out by the European Foundation for the Improvement of Living and Working Conditions in Dublin are the main source of information (6-9). The four surveys from 1990, 1995, 2000, and 2005, covered the 15 Western European Union (EU) member states and demonstrated two trends: (i) the work pace and exposure to tight deadlines have increased, in particular during the first half of the period, and (ii) control over work pace and work methods has increased, with the changes being more pronounced during the first five years. With regard to the other psychosocial indicators, including job satisfaction, there were no clear trends.

Covering the period 1989-1997, a survey of seven member countries of the Organization for Economic Cooperation and Development (OECD) showed a similar picture (10). The proportion of women reporting hard work increased. For both genders, more employees would prefer to spend less time on their job but they also reported improved job content. Job satisfaction was constant.

Gallie studied the development of quantitative demands at work from 1996-2001 in the 15 Western EU countries (11) and found that work pressure showed remarkable stability in all countries except Germany, where work pressure decreased.

This general picture of Western Europe has been supplemented by national studies in a number of countries. In the Netherlands, Smulders et al reported that work pace and time pressure were rather constant from 1994-2004 (12), while control over work pace, breaks, and work methods increased. Job satisfaction was constant. Clark found decreasing job satisfaction in the UK from 1992-1999 (10), while Theorell reported increased work pressure and decreased job control in Sweden, during the 1990s (13). Looking at Denmark, Burr concluded that quantitative demands, work pace, and emotional demands increased from 2000-2005 (14). During the same period, decision authority and social support from supervisors also increased, whereas role clarity decreased. Job satisfaction and job insecurity were stable during the period.

With regard to offensive behavior, we still have insufficient data from most countries. According to a 2005 report from the European Foundation for the Improvement of Living and Working Conditions, violence and intimidation increased in Europe from 1996-2000, whereas sexual harassment increased for women only (9). Data from Finland showed a steady increase in threats of violence (1984-2003), bullying
(1997-2003), and sexual harassment (2000-2003). In the Netherlands, there were small increases in violence, bullying, and sexual harassment from 2000-2003.

With some variation between countries, there seems to have been an overall trend of increasing quantitative demands in Western Europe - at least for the period 1990-1995. During the period 1990-2000, most countries experienced increasing job control. The other factors measured, such as job satisfaction, job content, and social support showed no clear trends. The data available on offensive behavior, albeit limited, seem to indicate an increasing trend.

Before presenting the results of the present study, a brief description of the Danish labor market may be useful. Denmark has the highest employment rate for women in the EU ( $72 \%$ versus $56 \%$ on average in the EU) (15). This is related to the almost universal use of pre-schools for children, free home care and institutions for the elderly, free public healthcare, and universal paid maternity leave of 30 weeks. Union membership rate for employees is approximately $75 \%$. The labor market is characterized by the so-called "flexicurity" model, combining high flexibility of the workforce with high levels of security (eg, compensation for wage loss when sick or unemployed) (16). This model implies that it is easy for employers to fire and hire employees. The minimum wage is about $\$ 20$ per hour and Denmark's income distribution is among the most equal in the world. Surveys have shown that the Danish labor market is characterized by high job control, high skill discretion, low power distance, and high job satisfaction (17). Public authorities and labor market organizations give high priority to psychosocial factors at work (18). The government has, in collaboration with labor inspection authorities and labor market organizations, set ambitious goals for the improvement of the psychosocial work environment. Thus, in comparison with other countries, Denmark has good psychosocial working conditions, high awareness and recognition of psychosocial factors, as well as the political commitment to improve these factors over time.

In this paper, we compare and analyze the results of two national surveys of psychosocial factors at work. Although our main focus was on a detailed description of the development of psychosocial factors over time at the national level and in a number of subgroups, we also had a number of hypotheses. Due to the abovementioned labor market developments, we expected to find the following changes: increased workload and time pressure, decreased predictability, and increased levels of offensive behavior. With regard to the job factors of control and skill discretion, our expectations were mixed: the increased use of participative management practices together with the "export" of monotonous work processes to Asian countries point in one direction, while the introduction of new 
public management and Taylorisation in the service sector (eg, cleaning, call centres) point in the opposite direction $(2,4,10,11,19-21)$. Furthermore, we expected increased work-family conflict due to the spread of "work without boundaries" (22).

Since there is no reason to believe that the developments in a country are uniform in all groups, we chose to analyze the trends in groups defined by age, gender, and socioeconomic status. From a methodological point of view, this also strengthened the study.

\section{Methods}

The analyses in this paper were based on two national questionnaire surveys of working Danes aged 2059 years. The first study (study 1) took place in 1997 (23) and the second (study 2) in 2005 (24). The Copenhagen Psychosocial Questionnaire (COPSOQ I) was developed on the basis of study 1 (25), and a second version of the questionnaire (COPSOQ II) was developed based on study 2 (www.nrcwe.dk/COPSOQ). In both studies, the Danish Centralized Civil Register provided the names and addresses of a randomly selected sample of adult Danes (aged 20-59 years) with a permanent address in Denmark. Both studies had a response rate of $60 \%$. Respondents received a questionnaire and a stamped response envelope by mail. Non-respondents received two reminders, the second one with a new questionnaire. In study 2, non-respondents were contacted a third time by telephone and asked to fill in the questionnaire and, if necessary, a new questionnaire was mailed to the respondents. One third of the population in study 1 was randomly selected for telephone interview. This group was not included in this paper in order to ensure comparability between the two studies, since it has been shown that the two study methods may give slightly different results (26). The response rate for the mailed questionnaire group in study 1 was $58 \%$. In study 2 , the respondents could choose to complete the questionnaire online, an option used by $10.4 \%$ of the respondents. The final sample comprised 1062 respondents from study 1 and 3517 from study 2 .

The Danish Centralized Civil Register provided information on gender and age; socioeconomic status was based on self-reported information from the questionnaire. The characteristics of the two samples with regard to gender, age, and socioeconomic status can be seen in table 1.

Most of the psychosocial factors were measured with multi-item scales $(25,27)$. All scales were scored from $0-100$, and each item in the scale was given the same weight. Most questions had five response options, corresponding to the scores $0,25,50,75$, and 100 . Respondents who had answered less than half of the questions in a scale were scored as missing on the particular scale. For more details about the questionnaire, see Kristensen et al (25).

In order to make comparisons between the studies possible, we only included questions asked in both studies which had exactly the same response options. In COPSOQ II, the maximum number of items in a scale was four, which means that the comparisons in our study were based on scales with 2-4 items. However, for work pace and demands for hiding emotions, the comparison was based only on a single item. The comparison was made based on 17 scales (including the 2 single items) covering different aspects of the psychosocial work environment, 2 scales covering job satisfaction and work-family conflict and 6 single items covering offensive behavior. The scales, the Cronbach's alphas for internal reliability, and the numbers of missing values on the scales are shown in table 2.

We performed a non-respondent analysis using logistic regression. We tested whether gender, age group, and degree of urbanization could predict if a person would respond to the questionnaire. Based on municipality codes, the degree of urbanization was categorized into: densely populated area, semi-densely populated area, or

Table 1. Distribution on gender, age, and socioeconomic status of the two national studies of the psychosocial work environment.

\begin{tabular}{|c|c|c|c|c|c|c|c|c|c|c|c|c|}
\hline & \multirow{2}{*}{$\begin{array}{c}\text { Number } \\
\text { of } \\
\text { respondents }\end{array}$} & \multirow{2}{*}{$\begin{array}{l}\text { Women } \\
\qquad \%)\end{array}$} & \multirow{2}{*}{$\begin{array}{l}\text { Mean } \\
\text { age } \\
\text { (years) }\end{array}$} & \multicolumn{4}{|c|}{ Age in years $(\%)$} & \multicolumn{5}{|c|}{ Socioeconomic status (\%) } \\
\hline & & & & $20-29$ & 30-39 & $40-49$ & $50-59$ & $I^{b}$ & $\| c$ & III d & IVe & $V^{\dagger}$ \\
\hline Study 1, 1997 & 1062 & 51.2 & 39.9 & 19.8 & 28.4 & 28.9 & 22.9 & 13.3 & 47.5 & 16.2 & 21.1 & 2.0 \\
\hline Study 2, 2005 & 3517 & 52.6 & 42.3 & 13.5 & 26.4 & 30.3 & 29.8 & 12.2 & 51.2 & 17.8 & 16.8 & 2.1 \\
\hline
\end{tabular}

a All respondents answered by mail or Internet (study 2) and were employees when responding.

b Professionals.

c White-collar workers.

d Skilled workers.

e Semi-skilled/unskilled workers.

f Other 
Table 2. Psychosocial dimensions included in the analyses. For all scales the number of items, missing values, and Cronbach alphas are shown.

\begin{tabular}{|c|c|c|c|c|c|}
\hline \multirow[t]{2}{*}{ Dimension } & \multirow[t]{2}{*}{$\begin{array}{l}\text { Number } \\
\text { of items }\end{array}$} & \multicolumn{2}{|c|}{$\begin{array}{l}\text { Cronbach's } \\
\text { alpha }\end{array}$} & \multicolumn{2}{|c|}{$\begin{array}{l}\text { Missing values } \\
\text { for the scales (\%) }\end{array}$} \\
\hline & & $\begin{array}{c}\text { Study } 1 \\
1997 \\
(\mathrm{~N}=1062)\end{array}$ & $\begin{array}{c}\text { Study } 2 \\
2005 \\
(\mathrm{~N}=3517)\end{array}$ & $\begin{array}{c}\text { Study } 1 \\
1997 \\
(N=1062)\end{array}$ & $\begin{array}{c}\text { Study } 2 \\
2005 \\
(\mathrm{~N}=3517)\end{array}$ \\
\hline Quantitative demands & 4 & 0.81 & 0.82 & 4.9 & 2.2 \\
\hline Work pace & 1 & - & - & 2.5 & 2.4 \\
\hline Cognitive demands ${ }^{a}$ & 4 & 0.79 & 0.74 & 5.1 & 2.2 \\
\hline Emotional demands & 3 & 0.88 & 0.86 & 3.8 & 2.2 \\
\hline $\begin{array}{l}\text { Demands for hiding } \\
\text { emotions }\end{array}$ & 1 & - & - & 4.2 & 3.0 \\
\hline Influence (control) a & 4 & 0.72 & 0.73 & 4.5 & 2.2 \\
\hline $\begin{array}{l}\text { Possibilities for } \\
\text { development }^{\mathrm{a}}\end{array}$ & 4 & 0.84 & 0.77 & 3.6 & 2.6 \\
\hline Variation ${ }^{\mathrm{a}}$ & 2 & 0.59 & 0.50 & 4.8 & 2.2 \\
\hline Meaning of work ${ }^{\mathrm{a}}$ & 3 & 0.79 & 0.74 & 3.8 & 2.8 \\
\hline $\begin{array}{l}\text { Commitment to the } \\
\text { workplace }^{\mathrm{a}}\end{array}$ & 2 & 0.67 & 0.67 & 4.3 & 2.6 \\
\hline Predictability a & 2 & 0.82 & 0.74 & 2.5 & 2.3 \\
\hline Role claritya & 3 & 0.80 & 0.78 & 5.5 & 2.7 \\
\hline Role conflicts & 4 & 0.73 & 0.67 & 5.5 & 2.6 \\
\hline Quality of leadership a & 4 & 0.89 & 0.89 & 5.3 & 4.6 \\
\hline $\begin{array}{l}\text { Social support from } \\
\text { supervisors }{ }^{a}\end{array}$ & 2 & 0.74 & 0.76 & 4.5 & 4.5 \\
\hline $\begin{array}{l}\text { Social support from } \\
\text { colleagues }^{a}\end{array}$ & 2 & 0.64 & 0.66 & 4.3 & 2.6 \\
\hline Sense of community a & 3 & 0.82 & 0.85 & 5.0 & 2.6 \\
\hline Job satisfaction ${ }^{a}$ & 4 & 0.82 & 0.82 & 5.4 & 2.8 \\
\hline Work-family conflict & 2 & 0.58 & 0.62 & 1.5 & 2.8 \\
\hline Sexual harassment & 1 & - & - & 3.9 & 3.3 \\
\hline Conflicts at work & 1 & - & - & 4.5 & 2.5 \\
\hline Threats of violence & 1 & - & - & 3.7 & 3.2 \\
\hline Physical violence & 1 & - & - & 4.2 & 3.3 \\
\hline Slander, gossip & 1 & - & - & 1.6 & 2.6 \\
\hline Unpleasant teasing & 1 & - & - & 4.3 & 3.2 \\
\hline
\end{tabular}

${ }^{a}$ High scale values are considered to have a positive effect on health.

sparsely populated area (28). To test for differences in the two subsamples, all two-level interactions between the main variables and study of origin (study 1 or study 2) were included in the analysis.

In order to clarify whether the measuring instrument was stable over time, we analyzed differential item functioning (DIF) in relation to time using ordinal logistic regression methods (29). In each analysis, the dependent variable was the specific item, while the independent predictors were the scale score and the background variable time. Analyzing the DIF for an item required a significant association of sufficient magnitude between the item and the variable time when controlling for the scale score. In accordance with other studies (30), a sufficient magnitude for the association required that the time variable explained at least an additional $2 \%$ of the item variance [using the difference in Nagelkerke's Pseudo R²(31)].
In the analyses of the time trends in the psychosocial factors between the two studies, we used the t-test for independence for the scales and the chi square test for the single items of offensive behavior. In addition, we calculated the adjusted means (least square means) for the scales and adjusted for differences in gender, age, and socioeconomic status corresponding to the categories which are shown in table 1 . We used a significance level of $5 \%$ and tested interaction effects between time trends and subgroups using analyses of variance. The significance level in these tests was narrowed to $1 \%$ to account for mass significance.

Finally, we evaluated the sensitivity of the trends found by weighting the scores for 2005 by the composition of the 1997 sample. This was done to assess a possible effect of the difference in the composition of the two subsamples with respect to gender, age, and socioeconomic status.

\section{Results}

The non-respondent analysis showed that the response rate for the overall sample differed for gender $(\mathrm{P}<0.0001)$ and age group $(\mathrm{P}<0.0001)$. Significant interactions effects with study were seen for gender $(\mathrm{P}=0.02)$ and especially age group $(\mathrm{P}=0.0001)$. All other effects were not significant. The response rate for men was $54 \%$ in both studies while the response rate for women was slightly higher in study $2(66 \%)$ than in study $1(62 \%)$. The response rates in the different age groups in study 1 were: 57\% (20-29 years), 62\% (30-39 years), 60\% (40-49 years) and 54\% (50-59 years). In study 2, we found an increase in the response rate with increasing age $(55 \%, 59 \%, 63 \%$, and $64 \%$, respectively).

Before comparing the psychosocial work environments in 1997 and 2005, it is relevant to consider the changes in the composition of the respondents. Table 1 shows two major changes: first, the average age increased by more than two years. Second, the proportion of white collar workers was about $4 \%$ higher in study 2 , while the proportion of semi-skilled/unskilled workers decreased by about $4 \%$.

Table 2 shows acceptable Cronbach's alpha values for internal reliability for most of the scales in the two studies. Values below 0.70 were seen for scales with only two items as expected: variation, commitment to the workplace, social support from colleagues, and work-family conflict. The alpha values in this paper are slightly different from the values previously published for study 1 (25), which is due to the fact that our study was restricted to items used in both studies and those respondents who answered by mail in study 1 . The percentages of missing values for the scales were low 
Table 3. Comparison of the levels on the psychosocial dimensions in the two studies. Average values and prevalence proportions. Number of significant $(P<0.05)$ changes: negative $=11$ and positive $=2$. [Parentheses () indicate non-significant direction of change]

\begin{tabular}{|c|c|c|c|c|c|c|c|c|}
\hline \multirow[t]{2}{*}{ Psychosocial dimension } & \multicolumn{2}{|c|}{$\begin{array}{l}\text { Study } 1,1997 \\
\quad(N=1062)\end{array}$} & \multicolumn{2}{|c|}{$\begin{array}{l}\text { Study } 2,2005 \\
\quad(N=3517)\end{array}$} & \multicolumn{2}{|c|}{ Difference } & \multirow[t]{2}{*}{ P-value } & \multirow[t]{2}{*}{$\begin{array}{l}\text { Direction } \\
\text { of change }\end{array}$} \\
\hline & Mean & $\begin{array}{c}\text { Prevalence } \\
\text { proportion } \\
\quad(\%)\end{array}$ & Mean & $\begin{array}{c}\text { Prevalence } \\
\text { proportion } \\
\qquad \%)\end{array}$ & Mean & $\begin{array}{c}\text { Prevalence } \\
\text { proportion } \\
\quad(\%)\end{array}$ & & \\
\hline Quantitative demands & 39.1 &.. & 40.2 & .. & 1.1 & .. & 0.13 & (Negative) \\
\hline Work pace & 59.0 &.. & 62.0 &.. & 3.0 &.. & 0.0002 & Negative \\
\hline Cognitive demands & 63.1 &.. & 63.9 &.. & 0.8 &.. & 0.26 & (Positive) \\
\hline Emotional demands & 38.9 &.. & 39.7 &.. & 0.8 &.. & 0.33 & (Negative) \\
\hline Demands for hiding emotions & 33.8 &.. & 35.1 &.. & 1.3 &.. & 0.16 & (Negative) \\
\hline Influence (job control) & 53.3 &.. & 49.8 &.. & -3.5 &.. & $<0.0001$ & Negative \\
\hline Possibilities for development & 69.5 &.. & 65.9 &.. & -3.6 &.. & $<0.0001$ & Negative \\
\hline Variation & 61.0 &.. & 60.4 & .. & -0.6 & .. & 0.41 & (Negative) \\
\hline Meaning of work & 77.6 &.. & 73.8 &.. & -3.8 &.. & $<0.0001$ & Negative \\
\hline Commitment to the workplace & 56.8 & .. & 58.1 &.. & 1.3 & .. & 0.10 & (Positive) \\
\hline Predictability & 57.5 &.. & 57.7 &.. & 0.2 & .. & 0.81 & (Positive) \\
\hline Role clarity & 76.0 &.. & 73.5 &.. & -2.5 &.. & $<0.0001$ & Negative \\
\hline Role conflicts & 36.7 &.. & 42.0 &.. & 5.3 &.. & $<0.0001$ & Negative \\
\hline Quality of leadership & 52.6 &.. & 55.3 &.. & 2.7 &.. & 0.0011 & Positive \\
\hline Social support from supervisors & 64.1 &.. & 69.6 & .. & 5.6 &.. & $<0.0001$ & Positive \\
\hline Social support from colleagues & 68.2 &.. & 64.1 &.. & -4.1 &.. & $<0.0001$ & Negative \\
\hline Sense of community & 80.0 &.. & 78.7 &.. & -1.3 &.. & 0.0454 & Negative \\
\hline Job satisfaction & 65.5 &.. & 65.3 &.. & -0.2 &.. & 0.69 & (Negative) \\
\hline Work-family conflict & 36.8 &.. & 38.2 & .. & 1.4 & .. & 0.13 & (Negative) \\
\hline Sexual harassment &.. & 1.9 &.. & 2.9 & .. & 1.0 & 0.0616 & (Negative) \\
\hline Conflicts at work &.. & 41.1 &.. & 51.2 &.. & 10.1 & $<0.0001$ & Negative \\
\hline Threats of violence &.. & 5.7 &.. & 7.8 &.. & 2.1 & 0.0195 & Negative \\
\hline Physical violence &.. & 2.7 &.. & 3.9 &.. & 1.2 & 0.0602 & (Negative) \\
\hline Slander, gossip &.. & 17.5 &.. & 38.9 &.. & 21.4 & $<0.0001$ & Negative \\
\hline Unpleasant teasing &.. & 6.8 &.. & 8.3 &.. & 1.5 & 0.1289 & (Negative) \\
\hline
\end{tabular}

in both studies, but in general, they were a bit higher for study 1 than study 2 .

Table 3 shows average scale values and prevalence proportions in the two studies and also the changes from study 1 to study 2 . We distinguished between "negative" and "positive" changes in order to simplify the overview of results. We analyzed the associations between the work environment variables and health effects in our data and in other studies $(32,33)$. These analyses gave consistent results indicating the direction of the associations with health.

Two of the positive changes were statistically significant: higher quality of leadership and increased social support from supervisors (table 3 ). Of the negative changes, 11 were statistically significant: higher work pace, less influence at work (job control), less possibilities for development (skill discretion), lower level of meaning of work, decreased role clarity, more role conflicts, less social support from colleagues, reduced sense of community at work, increased conflicts at work, more threats of violence, and more slander and gossip.

In table 4, the time trends are shown for, respectively, gender, the four age groups, and the four socioeconomic groups. The table shows no major inconsistencies in these developments. Thus, there are no cases of a positive development in one subgroup and a negative development in another. The trends were much the same for both men and women, even though we found more significant negative changes for woman than for men. However, our tests showed no systematic interaction effects (data not shown).

All age-specific developments were in accordance with the general development. The negative trends were seen for two, three, or all four age groups. The same was the case for the positive developments.

For the developments in the four socioeconomic groups, there were some differences between the four groups with regard to the overall pattern (table 4). For the professionals (group I) and the white-collar workers (group II) there were, respectively, 10 and 11 significant negative developments and 2 positive developments. For the skilled workers (group III), there were 4 negative and 4 positive developments, while there were 4 negative and 1 positive development for the semiunskilled/unskilled workers (group IV). However, our analysis of variance showed no systematic interaction effects between the study and socioeconomic status (data not shown). 
Table 4. Differences with regard to the development of psychosocial factors over time for gender, age groups and socioeconomic status. Only significant changes are shown. (neg = negative change; ${ }_{\text {pos }}=$ positive change)

\begin{tabular}{|c|c|c|c|c|c|c|c|c|c|c|}
\hline \multirow[t]{2}{*}{ Psychosocial dimension } & \multicolumn{2}{|c|}{ Gender } & \multicolumn{4}{|c|}{ Age groups (years) } & \multicolumn{4}{|c|}{ Socioeconomic status } \\
\hline & Women & Men & $20-29$ & $30-39$ & $40-49$ & $50-59$ & I & $11^{\mathrm{b}}$ & $\| I^{c}$ & IVd \\
\hline Quantitative demands & .. & .. & .. & .. & .. & .. & .. & $2.7_{\text {neg }}{ }^{\dagger}$ & .. & .. \\
\hline Work pace & $2.5_{\text {neg }}^{e}$ & $3.5_{\text {neg }}^{f}$ &.. & $2.8_{\text {neg }} \mathrm{e}^{\mathrm{a}}$ & .. & $4.6_{\text {neg }}{ }^{\dagger}$ & $4.1_{\text {neg }}^{e}$ & $4.6_{\text {neg }}{ }^{g}$ &.. & .. \\
\hline Cognitive demands & $\cdot \cdot$ & $\cdot$. &.$\cdot$ & $\cdot \cdot$ & .. &.$\cdot$ & $2.9_{\mathrm{pos}}^{\mathrm{e}}$ & $\cdot \cdot$ &.$\cdot$ & .. \\
\hline Emotional demands &.. &.. &.. &.. & .. &.. &.. &.. & $5.0_{\text {neg }}^{e}$ & .. \\
\hline Demands for hiding emotions &.. &.. &.. &.. & .. & .. & .. &.. &.. & .. \\
\hline Influence (job control) & $-3.5_{\text {neg }}{ }^{9}$ & $-3.3_{\text {neg }}^{\dagger}$ &.. & $-3.7_{\text {neg }}{ }^{e}$ & $-4.3_{\text {neg }}{ }^{\dagger}$ & $-4.6_{\text {neg }}^{\dagger}$ & $-3.2_{\text {neg }}^{e}$ & $-4.3_{\text {neg }}{ }^{9}$ & .. & .. \\
\hline Possibilities for development & $-3.9_{\text {neg }}^{9} 9$ & $-3.3_{\text {neg }}^{9}$ & .. & $-5.9_{\text {neg }}^{9}$ & $-3.2_{\text {neg }}^{\dagger}$ &.$\cdot$ & $-3.5_{\text {neg }}^{\mathrm{f}}$ & $-5.9_{\text {neg }}^{9}$ & $-3.2_{\text {neg }}^{e}$ & .. \\
\hline Variation &.$\cdot$ &.$\cdot$ &.$\cdot$ &.$\cdot$ & .. &.$\cdot$ & $-4.7_{\text {neg }}^{\dagger}$ & $\cdot$. &.$\cdot$ & .. \\
\hline Meaning of work & $-4.1_{\text {neg }}{ }^{9}$ & $-3.3_{\text {neg }}{ }^{9}$ &.. & $-5.5_{\text {neg }}{ }^{9}$ & $-3.7_{\text {neg }}{ }^{9}$ & $-4.5_{\text {neg }}{ }^{9}$ & $-4.6_{\text {neg }} 9$ & $-4.5_{\text {neg }}{ }^{9}$ &.. & $-3.9_{\text {neg }}^{\dagger}$ \\
\hline Commitment to the workplace &.. &.. & $4.3_{\mathrm{pos}}^{\mathrm{e}}$ &.. & .. &.. &.$\cdot$ &.. & $3.9_{\mathrm{pos}}^{\mathrm{e}}$ & .. \\
\hline Predictability & .. & .. &.. &.. & .. &.. &.. &.. & $4.7_{\text {pos }}^{\mathrm{e}}$ & .. \\
\hline Role clarity & $-3.6_{\text {neg }}{ }^{9}$ &.$\cdot$ &.$\cdot$ & $-3.6_{\text {neg }}^{\dagger}$ & $-1.6_{\text {neg }}{ }^{g}$ & $-4.0_{\text {neg }}{ }^{9}$ &.$\cdot$ & $-3.0_{\text {neg }}{ }^{9}$ &.$\cdot$ & .. \\
\hline Role conflicts & $5.6_{\text {neg }}{ }^{9}$ & $5.0_{\text {neg }}{ }^{9}$ & $6.2_{\text {neg }}{ }^{9}$ & $3.9_{\text {neg }}^{9}$ & .. & $5.6_{\text {neg }}{ }^{9}$ & $7.8_{\text {neg }}{ }^{9}$ & $5.3_{\text {neg }}{ }^{9}$ & $4.8_{\text {neg }}^{\dagger}$ & $4.1_{\text {neg }}^{\dagger}$ \\
\hline Quality of leadership & & $2.8_{p o s}^{e}$ & $4.5_{\mathrm{pos}}^{\mathrm{e}}$ & $4.6_{p o s}^{\dagger}$ & .. &.$\cdot$ &.$\cdot$ & $2.9_{\text {pos }}^{\dagger}$ & $5.3_{\text {pos }}^{\dagger}{ }^{\dagger}$ & .. \\
\hline Social support from supervisors & $4.6_{\mathrm{pos}}{ }^{9}$ & $6.4_{\mathrm{pos}}{ }^{9}$ & $5.0_{p o s} \mathrm{e}^{\mathrm{p}}$ & $6.5_{\text {pos }}^{9}$ & $6.2_{\mathrm{pos}}{ }^{9}$ & $4.8_{\text {pos }}^{e}$ & $10.0_{\text {pos }}^{e}$ & $5.3_{\mathrm{pos}}{ }^{\mathrm{p}}$ & $4.8_{\mathrm{pos}}^{\mathrm{e}}$ & $6.7_{\mathrm{pos}}^{\dagger}$ \\
\hline Social support from colleagues & $-4.0_{\text {neg }}{ }^{9}$ & $-4.2_{\text {neg }}{ }^{9}$ &.. & $-3.6_{\text {neg }}^{\dagger}$ & $-3.4_{\text {neg }}{ }^{\mathrm{e}}$ & $-5.7_{\text {neg }}{ }^{9}$ & $-6.3_{\text {neg }}^{\dagger}$ & $-3.9_{\text {neg }}{ }^{9}$ &.. & $-4.2_{\text {neg }}{ }^{\mathrm{e}}$ \\
\hline Sense of community & $-2.5_{\text {neg }}^{\dagger}$ & $\cdot \cdot$ &.$\cdot$ & $\cdot \cdot$ & .. & $-2,8_{\text {neg }}{ }^{e}$ &.$\cdot$ & $-2.0_{\text {neg }}{ }^{\mathrm{e}}$ &.$\cdot$ & .. \\
\hline Job satisfaction &.. &.. &.. &.. & .. &.. &.. &.. &.. & .. \\
\hline Work-family conflict &.$\cdot$ & .. & .. & .. & .. & .. & $5.1_{\text {neg }} \mathrm{e}^{\mathrm{e}}$ & $\cdot$. & $\cdot$. & .. \\
\hline Sexual harassment (\%) & $2.3_{\text {neg }}^{e}$ &.. &.. & .. &.. &.. &.$\cdot$ &.. & .. & .. \\
\hline Conflicts at work (\%) & $8.3_{\text {neg }}{ }^{g}$ & $12.0_{\text {neg }}{ }^{9}$ & $10.7_{\text {neg }}^{e}$ & $9.3_{\text {neg }}^{\dagger}$ & $13.0_{\text {neg }}{ }^{9}$ & $9.4_{\text {neg }}^{\dagger}$ & $14.9_{\text {neg }}^{\dagger}$ & $10.5_{\text {neg }}{ }^{9}$ &.. & .. \\
\hline Threats of violence (\%) & $3.0_{\text {neg }}$ e & $\cdot$. & $\cdot$. &.. & $\cdot$. & $4.4_{\text {neg }}^{\mathrm{g}} \mathrm{e}$ & $\cdot \cdot$ & $\cdot \cdot$ &.$\cdot$ & .. \\
\hline Physical violence (\%) &.. & .. & .. & .. & .. &.. & .. & .. & .. & .. \\
\hline Slander, gossip (\%) & $23.4_{\text {neg }}{ }^{9}$ & $19.2_{\text {neg }}{ }^{9}$ & $33.2_{\text {neg }}{ }^{9}$ & $24.8_{\text {neg }}{ }^{9}$ & $18.9_{\text {neg }}^{9}$ & $15.7_{\text {neg }}{ }^{9}$ & $22.0_{\text {neg }}{ }^{9}$ & $19.9_{\text {neg }}{ }^{9}$ & $23.1_{\text {neg }}{ }^{9}$ & $23.3_{\text {neg }}{ }^{9}$ \\
\hline Unpleasant teasing (\%) .. & .. & .. & .. & & .. &.. &.$\cdot$ &.. &.. & \\
\hline Number, significant negative changes & 12 & 8 & 3 & 9 & 7 & 9 & 10 & 11 & 4 & 4 \\
\hline Number, significant positive changes & 1 & 2 & 3 & 2 & 1 & 1 & 2 & 2 & 4 & 1 \\
\hline Study $1(\mathrm{~N})$ & 544 & 518 & 210 & 302 & 307 & 243 & 141 & 504 & 172 & 224 \\
\hline Study 2 (N) & 1849 & 1668 & 475 & 930 & 1065 & 1047 & 428 & 1799 & 626 & 589 \\
\hline
\end{tabular}

a Professionals.

${ }^{b}$ White-collar workers.

c Skilled workers.

d Semi-skilled/unskilled workers.

e $P<0.05$.

if $P<0.01$.

${ }_{9} \mathrm{P}<0.001$.

As a supplement to the stratified analyses, we calculated the means for the scales in the two studies and adjusted for differences in the two populations with regard to gender, age, and socioeconomic status (data not shown). This analysis gave the same overall picture of the time trend as for the unadjusted means.

In analyzing the sensitivity of the trends, we evaluated the influences of a changed composition in the two samples (table 1). The effects of the change in the composition of the two subsamples were very modest on the significant trends (table 2). On average, the effect of a changed gender composition overestimated the magnitudes of the actual trends by $0.7 \%$ (range $-5-2 \%$ ). A change in the composition of socioeconomic status underestimated the trends by, on average, $0.3 \%$ (range $-10-12 \%$ ) and a change in composition of the age of the respondents underestimated the trends by on average $3.1 \%$ (range $-13-12 \%$ ).

Finally, we analyzed the issue of DIF. None of the scales contained items with a statistically significant DIF with respect to time of a magnitude which fulfilled our criterion (30). Two items in quantitative demands ("Is your work unevenly distributed so it piles up?" and "Do you get behind with your work?") came close to the criterion of $2 \%$, as time explained an additional $1.5 \%$ and $1.8 \%$, respectively, of the item variance. For all other items, time only explained, on average, an additional $0.2 \%$ (range $0.0-0.7 \%$ ) of the item variance. The score on the item "work piles up" went from 50.2 to 44.5 , whereas the development on the item "getting behind" was in the opposite direction from 30.5 to 38.9. Thus, the stability of the measure of quantitative 
demands was the result of two opposing developments of two items and the stability of two other items, but it was not regarded as a substantial magnitude in relation to the common criterion for DIF (30).

\section{Discussion}

Our study had a number of strengths. First, the study population was a randomly selected national sample based on personal registration numbers. Second, the survey instrument was a well-validated tool covering a broad range of psychosocial work environment factors $(23,25-27,34,35)$. Many previous studies of developments over time only covered a limited range of factors. Third, we not only analyzed the overall trends, but also differential patterns with regard to age, gender, and socioeconomic status.

The study also had a number of weaknesses. The non-response analysis showed that the sample was not fully representative with regard to gender and age (ie, more women responded than men and more older than younger people), which limits the generalization of the results. This may bias the results in favor of the more stable work environment characteristics of middle-aged employees. The analysis also showed a difference in the response rates for gender and age group between the two studies. The pattern in response rates fits well with the changing distribution of the two samples with regard to gender and age (table 2) indicating the change in the composition of the sample may partly be due to the changed response rates rather than a change in the Danish labor force.

However, the age difference in the two samples is partly explained by survey exemption. Since 2000, when Danish citizens change address, they have the option to indicate on their change of address form, whether they would like to be exempt from surveys (36). Hence, when the sample for study 2 was drawn, approximately $10 \%$ of the population was exempt from surveys. Young people move more often and survey exemption is 4 times more common in the age group 20-29 years than in the age group 50-59 years. Therefore, survey exemption and a lower response rate resulted in some under-representation in the 20-29 year old age group in study 2 . The lower representation of younger males may very well explain the decrease in the proportion of semiskilled/unskilled workers at the expense of white-collar workers.

The effect of the change in the composition of the two samples with regard to gender, age, and socioeconomic status was estimated to be minor, and if anything, it tended to underestimate the trends found. We, therefore, do not think that the trends were influenced by the relatively small difference in the composition of the two study samples.

Another potential weakness could have been the changes over time with regard to the general perception and evaluation of psychosocial factors in the Danish population. Goliembiewski et al refer to this as a gamma change (37). Stress and psychosocial factors have been "hot topics" in the Danish media during the past decade, which could result in increased awareness of these factors. It is difficult to assess the bias due to this phenomenon, but the differential picture of the development over time seems to suggest that the respondents were able to assess the different factors in a nuanced and valid way. A possible bias could also be that the measuring instrument has changed over time, referred to as a beta change (37). However, our analyses showed no significant time DIF of a magnitude that fulfilled the common criterion (30). All in all, we do not have any indication that beta or gamma changes occurred and regard the changes found in the psychosocial work environment as alpha changes or true changes (37).

Denmark could be regarded as a "best case" within the field of psychosocial work environment and, therefore, one may argue that the changes we found were due to regression to the mean. However, the differential picture, with both positive and negative developments, indicated that this was unlikely.

Our main conclusion is that the psychosocial work environment of Danish employees has deteriorated during the period under study. Our stratified analyses showed the same pattern as the overall analysis, since we found no significant inconsistencies. Furthermore, we did not find any significant interaction effect in our analyses. Thus, the deterioration of the psychosocial work environment was seen in all subgroups and not just among certain groups of employees.

As stated in the introduction, one of the major international trends has been the increase in quantitative demands at work. In COPSOQ II, we distinguished between quantitative demands (deadlines and high workload) and work pace (high tempo). This is the result of previous analyses in which we found evidence for distinguishing between "extensive" and "intensive" demands at work (27). In the present study, we did not find any statistically significant increase in our scale on quantitative demands at work, but an increase in work pace. However, an analysis of the individual items in the scale on quantitative demands showed an increasing proportion of employees reporting that they often get behind with their work and a decrease in the proportion with an uneven workload. Thus, we have evidence for an increase in work pace and also in the proportion getting behind with work. These results correspond to international results on this topic. 
One of the clearest results of our study was the increase in employees who reported being exposed to offensive behavior. In particular, we found sharp increases regarding conflicts at work and slander and gossip. This is in line with the few international studies mentioned in the introduction. In view of the serious consequences of being exposed to offensive behavior (38-40), this development is worrying.

Our results concerning influence and possibilities for development are at odds with the developments reported for other countries. This could be due to the fact that Denmark already had a very high level with regard to these factors (ceiling effect), or to the introduction of some of the managerial practices mentioned in the introduction such as new public management and neo-Taylorization in the service sector.

Concerning collaboration and leadership, our results were mixed. On the one hand, we saw negative developments for role conflicts, role clarity, and social support from colleagues. But on the other hand, we observed positive trends for quality of leadership and support from supervisors. The improvements in the factors related to leadership are noteworthy. Denmark has experienced a dramatic change in the prevailing attitudes to leadership during the last two to three decades. In the 1970s, strong egalitarian attitudes were dominant and supervisors/leaders/managers were considered a "necessary evil". Today, this has changed completely. Good and visible leadership is highly valued, training of supervisors is being given high priority, and good leadership is considered to be a key factor in the psychosocial work environment. According to the Danish Association of Managers and Executives, the number of managers attending courses in leadership training has more than doubled during the period under study (41). In the light of these changes in society, it is interesting to see that the employees reported improvements in the two factors related directly to leadership behavior.

The Danish work environment has been surveyed every fifth year since 1990 in the Danish Work Environment Cohort Study (DWECS) (42). The psychosocial dimension studied in DWECS for 2000 and 2005 are based on COPSOQ even though the number of dimensions are smaller. Furthermore, the comparison with DWECS can only be made based on telephone interview (14). DWECS and the COPSOQ studies were compared on the dimensions: work pace, emotional demands, social support from supervisors, quality of leadership, possibilities for development, meaning of work and influence. We found inconsistent results only for the dimension influence, where DWECS found a positive change from 2000 to 2005 . We do not have an explanation for this difference between the two studies.

The international literature shows that psychosocial factors have an impact not only on the well-being of employees but also disease risk, mortality, absence from work, job turnover, early exit from the workforce, motivation, productivity, and quality (43-49). Therefore, a deterioration in the psychosocial work environment of a whole country is disturbing. It is our judgement that the observed negative trends should be interpreted in light of the development of the globalised economy and the new trends in the public sector such as new public management. As mentioned in the introduction, increased competition and rate of change together with the rapid introduction of new management technologies may well lead not only to higher quantitative demands but also to a lack of predictability, lower meaning of work, loosening of social networks, more job insecurity, and decreased role clarity. Further international research is needed in order to elucidate international trends during this era of globalization.

Denmark has good psychosocial working conditions and a high level of commitment from both the government and the main organizational players to improve psychosocial working conditions. For this reason, the study should not be seen as a "replication study" in which we expect the same development as found in other countries. Our main finding was that, in spite of the political effort to improve the work environment, the overall tendency has been in the opposite direction - not only at the national level - but also for broad subgroups. This raises the question: to what extent can the state and labor market organizations influence the psychosocial work environment in a period where strong economic and social forces tend to pull in the opposite direction?

We did find one clear positive trend, namely the improvements with regard to leadership. As far as we know, very few other studies have measured this factor over time. As stated above, this development could be due to strong national emphasis on the importance of leadership during recent years. Perhaps this development could serve as a model for other factors in the psychosocial work environment.

It is noteworthy that almost all models and most research on psychosocial factors at work deal with the impact of work environment factors on health and health-related factors (21). If our goal is to understand the forces shaping and changing the work environment, this focus is clearly insufficient. We need theories and research regarding the factors that shape the psychosocial work environment of the future.

\section{Acknowledgements}

The authors would like to thank Jakob Bue Bjorner and Helene Feveile for their valuable support and assistance with the statistical analyses. 


\section{References}

1. National Institute of Occupational Safety and Health (NIOSH). The changing organization of work and the safety and health of working people. Cincinnati (OH): NIOSH; 2002. Publication number 116

2. Landsbergis PA The changing organization of work and the safety and health of working people: a commentary. J Occup Eviron Med. 2003;45:61-72.

3. Kompier MAJ. New systems of work organization and workers' health. Scand J Work Environ Health. 2006;32(6):421-30.

4. Handel MJ. Trends in perceived job quality, 1989 to 1998. Work Occup. 2005;32:66-94.

5. Bond JT, Galinsky E, Swanberg JE. The 1997 National Study of the Changing Workforce. New York (NY): Families and Work Institute; 1998.

6. Weiler A. Annual review of working conditions in the EU: 2005-2006. Dublin: European Foundation for the Improvement of Living and Working Conditions; 2006.

7. Paoli P, Merllié D. Third European survey on working conditions 2000. Dublin: European Foundation for the Improvement of Living and Working Conditions; 2001.

8. Houtman I. Work-related stress. Dublin: European Foundation for the Improvement of Living and Working Conditions; 2005.

9. European Foundation for the Improvement of Living and Working Conditions. Violence, bullying and harassment in the workplace. Dublin: European Foundation for the Improvement of Living and Working Conditions; 2007.

10. Clark AE. Your money or your life: changing job quality in OECD countries. Br J Ind Relat. 2005;43:377-400.

11. Gallie D. Work pressure in Europe 1996-2001: trends and determinants. Br J Ind Relat. 2005;43:351-75.

12. Smulders PGW. Worklife in the Netherlands. Hoofddorp (the Netherlands): TNO; 2006.

13. Theorell T. I spåren av 90-talet [Tracing the 90s]. Stockholm: Karolinska Institute University Press; 2006.

14. Burr H. Arbejdsmiljø i Danmark 2005 - psykosocialt arbejdsmiljø [Work environment in Denmark 2005 psychosocial work environment]. Copenhagen: National Institute of Occupational Health; 2006.

15. Giaccone M. Annual review of working conditions in the EU 2006-2007. Dublin: European Foundation for the Improvement of Living and Working Conditions; 2007.

16. Jørgensen H, Madsen PK, Jørgensen H, Madsen PK, editors. Flexicurity and beyond: finding a new agenda for the European Social Model. Copenhagen: DJØF Publishing; 2007.

17. Parent-Thirion A, Fernández Macías E, Hurme J, Vermeylen G. Fourth European Working Conditions Survey. Luxembourg: European Foundation for the Improvement of Living and Working Conditions; 2007.

18. Danish Work Environment Authority. 10 år med handlingsprogrammet 'Rent arbejdsmiljø år 2005' [10 years with the action programme "A Clean Work Environment"]. Copenhagen (Denmark): The Danish Working Environment Authority; 2007.
19. Tausig M, Fenwick R, Sauter SL, Murphy LR. The changing nature of job stress: risk and resources. In: Perrewé PL, Ganster DC, editors. Exploring interpersonal dynamics. Amsterdam (the Netherlands): Elsevier Ltd; 2005. p 93-126.

20. Murphy LR, Sauter SL. Work organization interventions: state of knowledge and future directions. Soz Präventivmed. 2004;49:79-86.

21. Kompier M. Job design and well-being. In: Schabracq MJ, Winnubst JAM, Cooper CL, editors. The handbook of work and health psychology. Chichester (UK): John Wiley \& Sons; 2003. p 429-54.

22. Allvin M. New rules of work: exploring the boundaryless job. In: Näswall K, Hellgren J, Sverke M, editors. The individual in the changing working life. New York (NY): Cambridge University Press; 2008. p 19-45.

23. Kristensen TS, Borg V, Hannerz H. Socioeconomic status and psychosocial work environment: results from a Danish national study. Scand J Public Health Suppl. 2002;59:41-8.

24. Ortega A, Hogh A, Pejtersen JH and Olsen O. Prevalence of workplace bullying and risk groups: a representative population study. Int Arch Occup Environ Health. 2009;82(3):417-26.

25. Kristensen TS, Hannerz H, Høgh A, Borg V. The Copenhagen Psychosocial Questionnaire - a tool for the assessment and improvement of the psychosocial work environment. Scand J Work Environ Health. 2005;31(6):438-49.

26. Feveile $\mathrm{H}$, Olsen $\mathrm{O}$, Hogh A. A randomized trial of mailed questionnaires versus telephone interviews: response patterns in a survey. BMC Med Res Methodol. 2007;7:27.

27. Kristensen TS, Bjorner JB, Christensen KB, Borg V. The distinction between work pace and working hours in the measurement of quantitative demands at work. Work Stress. 2004;18:305-22.

28. Eurostat. EU Labor Force Survey database: user guide: annex: explanatory notes. Brussels: European Commission; 2006.

29. Zumbo BD. A handbook on the theory and methods of Differential Item Functioning (DIF): logistic regression modeling as a unitary framework for binary and likert-type (ordinal) item scores. Ottawa (ON): Directorate of Human Resources Research and Evaluation, Department of National Defense; 1999

30. Bjorner JB, Kosinski M, Ware JE. Calibration of an item poo for assessing the burden of headaches: An application of item response theory to the Headache Impact Test (HIT (TM)). Qual Life Res. 2003;12:913-33.

31. Nagelkerke NJD. A note on a general definition of the coefficient of determination. Biometrika. 1991;78:691-2.

32. Borritz M, Bültmann U, Rugulies R, Christensen KB, Villadsen E, Kristensen TS. Psychosocial work characteristics as predictors for burnout: findings from 3-year follow up of the PUMA study. J Occup Environ Med. 2005;47:1015-25.

33. Rugulies R, Christensen KB, Borritz M, Villadsen E, Bültmann U, Kristensen TS. The contribution of the psychosocial work environment to sickness absence in human service workers: results from a 3-year follow-up. Work Stress. 2007;21:293-311. 
34. Nübling M, Stössel U, Hasselhorn HM, Michaelis M, Hofmann F. Measuring psychological stress and strain at work: evaluation of the COPSOQ questionnaire in Germany. Psychosoc Med. 2006;3:1-14.

35. Navarro A, LLorens C, Kristensen TS, Moncada i Luis S. ISTAS21: Versión en lengua castellana del cuestionario psicosocial de Copenhague (COPSOQ) [The Spanish version of the Copenhagen Psychosocial Questionnaire (COPSOQ)]. Arch Prev Riesgos Labor. 2005;8:18-29.

36. Thorsted, BL. Forskerbeskyttelse i CPR [Survey exemption in the Danish Centralized Civil Register]. In: Linde,P, editor. Symposium i anvendt statistik 30-31. Jannuar 2007 [Symposium in applied statistic, 30-31 January 2007]. Århus (Denmark): Århus University and Statistic Denmark; 2007. p 74-84.

37. Golembiewski RT, Billingsley K, Yeager S. Measuring change and persistence in human affairs - types of change generated by od designs. J Appl Behav Sci. 1976;12:133-57.

38. Einarsen S. Harassment and bullying at work: a review of the Scandinavian approach. Agress Violent Behav. 2000;5:379-401.

39. Hoel H, Sparks K, Cooper CL. The cost of violence/stress at work and the benefits of a violence/stress-free working environment. University of Manchester Institute of Science and Technology; 2000. Report Commissioned by the International Labor Organization (ILO), Geneva, (Switzerland).

40. Wieclaw J, Agerbo E, Mortensen PB, Burr H, Tüchsen F, Bonde JP. Work related violence and threats and the risk of depression and stress disorders. J Epidemiol Community Health. 2006;60:771-5.

41. Danish Association of Managers and Executives. Beretning for Ledernes Hovedorganisation [Annual report for the Danish Association of Managers and Executives]. Copenhagen
(Denmark): The Danish Association of Managers and Executives; 2006.

42. Burr H, Bjorner JB, Kristensen TS, Tüchsen F, Bach E. Trends in the Danish work environment in 1990-2000 and their associations with labor-force changes. Scand J Work Environ Health. 2003;29(4):270-9.

43. Belkic KL, Landsbergis PA, Schnall PL, Baker D. Is job strain a major source of cardiovascular disease risk? [review]. Scand J Work Environ Health. 2004;30(2):85-128.

44. Nurminen M, Karjalainen A. Epidemiologic estimate of the proportion of fatalities related to occupational factors in Finland. Scand J Work Environ Health. 2001;27(3):161-213.

45. Alexanderson K. Sickness absence: a review of performed studies with focused on levels of exposures and theories utilized. Scand J Soc Med. 1998;26:241-9.

46. Krause N, Lund T. Returning to work after occupational injury. In: Barling J, Frone MR, editors. The psychology of workplace safety. Washington (DC): American Psychological Association; 2004. p 265-95.

47. Spreitzer GM, Mishra AK. Giving up control without losing control - trust and its substitutes' effects on managers' involving employees in decision making. Group Organ Manage. 1999;24:155-87.

48. Gould-Williams J. The importance of HR practices and workplace trust in achieving superior performance: a study of public-sector organizations. Int J Human Resourc Manage. 2003;14:28-54.

49. Kahya E. The effects of job characteristics and working conditions on job performance. Int J Ind Ergon. 2007;37:515-523.

Received for publication: 24 November 2008 